\title{
ERİK (Prunus domestica) BAZLI KARIŞIK MEYVELİ GELENEKSEL MARMELAT ÜRETIMİ
}

\author{
Filiz Uçan Türkmen*, Büşra Nur Bingöl, Elif Şahin, \\ Funda Özkaraman, Zeynep Tekin
}

Kilis 7 Aralık Üniversitesi, Mühendislik-Mimarlık Fakültesi, Gıda Mühendisliği Bölümü, Kilis, Türkiye

Geliş/Received: 01.04.2019; Kabul/Accepted: 07.07.2019; Online bask1 / Published online: 25.07.2019

Uçan Türkmen, F., Bingöl, B.N., Şahin, E., Özkaraman, F., Tekin, Z. Erik (Prunus domestica) bazlı karışık meyveli geleneksel marmelat üretimi. GID A (2019) 44 (4): 707-718 doi: 10.15237/gida.GD19065

Uçan Türkmen, F., Bingöl, B.N., Şahin, E., Özkaraman, F., Tekin, Z. Production of tradational marmalade with mixed fruit based plum (Prunus domestica). GIDA (2019) 49 (4): $707-718$ doi: 10.15237/gida. GD19065

\section{ÖZ}

Bu araştırmada erik bazlı karışık meyveli geleneksel marmelat üretimi üzerine çalışılmıştır. \%100 Erik, \%75 erik- $\% 25$ kayıs $1, \% 75$ erik- $\% 25$ yabanmersini, $\% 50$ erik- $\% 25$ kayıs1- $\% 25$ yabanmersini oranlarnnda meyveler kullanılarak marmelat üretimleri gerçekleştirilmiştir. Üretilen marmelat örneklerinde ve meyve pulplarında pH, suda çözünür kuru madde, titrasyon asitliği, su aktivitesi, kül, renk, invert şeker, toplam fenolik madde, toplam flavonoid madde, antioksidan aktivite, askorbik asit ve duyusal analizler yapılmış ve örnekler istatistiksel olarak değerlendirilmişlerdir. En yüksek toplam fenolik madde (2.12 mg GAE/g-3.91 $2.12 \mathrm{mg}$ GAE/g) ve antioksidan aktivite (\%79.49-\%73.04) değerleri $\% 75$ erik- $\% 25$ kayıs1 pulp ve marmelatlarından elde edilmiştir. Duyusal değerlendirmede en çok beğenilen marmelatın 4.46 puan ile erik pulpundan üretilen örnek olduğu ve bunu azalan puan sirasına göre erik-kayısı-yabanmersini, erik-kayıs1, erik-yabanmersini pulplarından üretilen örneklerin takip ettiği belirlenmiştir. Bu çalışma yeni formüle edilmiş ürün gelişimine gerek duyan erik endüstrisine farklı meyvelerle karıştırlmış erik bazlı marmelat ile eriğe yeni bir kullanım alanı sağlanabileceğini göstermektedir.

Anahtar kelimeler: Erik, kayıs1, yaban mersini, marmelat, antioksidan aktivite

\section{PRODUCTION OF TRADATIONAL MARMALADE WITH MIXED FRUIT BASED PLUM (Prunus Domestica)}

\begin{abstract}
In this research, the production of traditional marmalade with mixed fruit based plum is studied. The production of marmalade was performed using $100 \%$ Plum, $75 \%$ plum- $25 \%$ apricot, $75 \%$ plum- $25 \%$ blueberry, $50 \%$ plum- $25 \%$ apricot- $25 \%$ blueberry. In the produced marmalade samples and fruit pulps, $\mathrm{pH}$, water soluble dry matter, titratable acidity, water activity, ash, color, invert sugar, total phenolics, total flavonoids, antioxidant activity, ascorbic acid and sensory analyzes were made and samples were evaluated statistically. The highest total phenolics (2.12 mg GAE/g-3.91 mg GAE/g) and antioxidant activity $(79.49 \%-73.04 \%$ ) were obtained from $75 \%$ plum- $25 \%$ apricot pulp and marmalade. It was determined that the most popular marmalade in sensory evaluation was the sample produced from plum pulp with a score of 4.46, followed by plum-apricot-blueberry, plum-apricot and plum cranberry pulp. This study shows that a new usage area can be provided with plum-based marmalade mixed with different fruits to the plum industry which needs new formulated product development.
\end{abstract}

Keywords: plum, apricot, blueberry, marmelade, antioxidant activity.

*Yazışmalardan sorumlu yazar / Corresponding author;

$\varangle$ ucanfiliz@gmail.com, @ O(+90) 348814 3096/1812

冝(+90) 3488143098 


\section{GİRİ̧̧}

Erik 'Prunus domestica', yeşil, sarı, kırmızı ya da mor renkli, ekşi ya da tatlı çeşit çeşit meyve veren erik ağaçları gülgiller familyasının Prunus cinsindendir. Kafkasya ve Hazar Deniz'i çevresinden dünyaya yayıldığ1 sanılmaktadır (Anonym., 2005a). Bugün Türkiye'de yetişen erik çeşitlerinin bir kısmı yerli, bir kısmı da yabancı çeşitlerdir (Anonym., 2005b). Erikler Prunus cerasifera (Yeşil erikler, Can erikler), $P$. salicina (Japon erikleri) ve $P$. domestica (Avrupa erikleri) olmak üzere üç türe ayrrlmaktadır. Bu türler içinde Can erikleri sofralık ve anaçlık olarak, Japon erikleri sofralık ve teknolojik (reçel, meyve suyu, marmelat vb) olarak, Avrupa erikleri ise kurutmalık ve sofralık olarak tüketilmeye uygundur (Anonym., 2005c). Ülkemizde üç farklı doğal mavi yemiş türü (Vaccinium myrtillus L., Vaccinium arctostaphylos L., Vaccinium uliginosum L.) bulunmaktadır. Özellikle kısıtlı tarım alanına sahip Karadeniz bölgesinin dağlık alanlarda yaşayan köylüler doğrudan doğadan meyve toplayıp ya da sahip oldukları küçük üretim alanlarını bu amaçla kullanıp sosyal ormancıllğa da önemli bir katkıda bulunmaktadır (Gültekin, 2010). Ülkemizde 2000’li yılların başlarında özellikle Doğu Karadeniz Bölgesinde boylu maviyemiş olarak adlandırılan boylu maviyemiş türünün birçok çeşidi (Brigitta, Bluecrop, Bluejay, Duke, Nelson, Earliblue, Patriot ve Spartan) ile adaptasyon denemeleri yapılmış ve başarılı sonuçlar elde edilmiştir (Çelik, 2006). Kayısının (Prunus armeniaca L.) anavatanının Çin'e kadar uzandığı ve Anadolu topraklarına girişinin iki bin yıldan fazla bir geçmişi olduğu bilinmektedir. Ülkemizde kays1 yetiştiriciliği yaygın olarak yapılmakla birlikte ekonomik olarak yetiştiriciliği bazı bölgelerimize kaymıştır. Malatya bölgesi, Elazığ-Erzincan-Sivas bölgesi, Akdeniz bölgesi, Kars-Iğdır bölgesi, Ege bölgesi, İç Anadolu bölgesi ve Marmara bölgesi farklı yoğunluk ve çeşit deseninde üretim yapmakta olup, tüm üretimin yarısından fazlasını Malatya bölgesi karşılamaktadır (Muradoğlu ve ark., 2011).

Geleneksel marmelat; meyve pulpu, püre, meyve suyu ve sulu ekstraktlarının veya bitkilerin kök, yaprak, çiçek gibi yenilebilen kısımlarının gerektiğinde şekerler ve su ilave edilerek sürülme kıvamına getirilmiş karışımdır (Anonymous,
2006). Türk Gıda Kodeksi'ne göre marmelat; su, şeker, meyve veya turunçgillerin bir veya birkaç çeşidinden elde edilen pulpun Türk Gıda Kodeksi Yönetmeliği'nde izin verilen katkı maddelerinin kullanılmasıyla uygun jel kıvamına getirilmiş karışımdır. Bu çalışmanın amacı, özellikle son ylllarda üretimi artış gösteren erik meyvesinin tüketiminin yaygınlaştırılması hedeflenerek yalın halde veya farklı meyveler ilavesiyle karış1k meyveli geleneksel marmelat üreterek elde edilen bu marmelatların bazı kalite özelliklerini incelemektir. $\mathrm{Bu}$ amaçla hedefimiz, besleyici değeri ve katma değeri yüksek marmelatın bazı fiziksel ve kimyasal özellikleri ile duyusal ve istatistiksel analizlerle elde edilen verilerden literatüre yeni bir ürün kazandırmaya çalışmak olmuştur.

\section{MATERYAL VE YÖNTEM \\ Materyal}

$\mathrm{Bu}$ çalş̧mada, ana materyal olarak Kilis ilindeki semt pazarından temin edilen Prunus domestica cinsi erikler; Vaccinum sp. çeşidi yabanmersini ve Prunus armeniaca L. çeşidi kayısılar kullanılmıştır. Meyveler temin işleminden hemen sonra zarar görmeyecek şekilde Kilis 7 Aralık Üniversitesi Gıda Mühendisliği laboratuvarına getirilmiştir. Laboratuvarımıza getirilen tüm meyveler marmelat üretimleri gerçekleştirilinceye kadar $+4 \pm 1^{\circ} \mathrm{C}$ 'de buzdolabı koşullarında muhafaza edilmiştir. Çalışmada marketten temin edilen ticari firmalara ait toz şeker (saf kristal sakkaroz), su, sitrik asit ve ayrıca ürünlerin ambalajlanmasinda ise $200 \mathrm{~mL}$ 'lik contalı twist-off kapaklı cam kavanozlar kullanılmıştır.

\section{Yöntem}

\section{Marmelat Üretimi}

Laboratuvara getirilen meyveler seçme, ayıklama, yıkama, sap ayırma ve çekirdek çıkarma ile tartım işlemlerinden sonra kabuklariyla birlikte blenderdan (Arzum, AR1041, Türkiye) geçirilerek homojen hale getirilmiştir. Marmelatların üretimi sırasında blender, elektrikli 1sıtıc1, açık kazanı temsilen tencere ve tahta spatuladan yararlanılmıştır. $\quad \mathrm{Bu}$ çalışmada, Türk Gida Kodeksi; "Reçel, Jöle, Marmelat ve Tatlandırılmış Kestane Püresi Tebliği'nde belirtilen geleneksel marmelat üretimi hedeflenerek aşağıda belirtilen 
reçete uygulanmıştır. Marmelat Reçetesi: $1000 \mathrm{~g}$ meyve pulpu, $1000 \mathrm{~g}$ şeker, \%25'lik sitrik asit çözeltisi (ürünün $\mathrm{pH}$ değeri 2.8-3.5 arasında olacak şekilde kontrollü olarak ilave edilmiştir) ve $300 \mathrm{ml}$ su'dur. Marmelat üretimi; a) \%100 Erik, b) $\% 75$ Erik ve $\% 25$ Kayıs1, c) $\% 75$ Erik ve $\% 25$ Yabanmersini, d) \%50 Erik, \%25 Kayı1 1 ve \%25 Yabanmersini olmak üzere 4 farklı formülasyon uygulanarak gerçekleştirilmiştir. Her bir marmelat formülasyonunda belirtilen oranlara uygun miktarda hazırlanan pulp ya da pulp karışımlarına reçetede belirtilen miktarlarda şeker ve su ilave edilerek örneklere açı kazanda pişirme (atmosferik basınçta) tekniği uygulanmıştır. Refraktometre ile kuru madde oranı aralıklarla ölçülerek pişirme süresi yaklaşık 30 dakika olacak şekilde tüm örneklere standart olarak uygulanmaya çalışılmıştır. Pişirme işleminin sonlarına doğru pH’1 2.8-3.5 olacak şekilde ayarlamak ve sakkarozun kismen inversiyonunu sağlamak amaciyla pişmekte olan ürün içerisine \%25 konsantrasyonda hazırlanan sitrik asit çözeltisi kontrollü olarak ilave edilmiş ve birkaç dakikalık pişirme işleminden sonra istenilen suda çözünen kuru maddeye ( $\geq 55$ Briks) ulaşıldığında pişirme işlemine son verilmiştir (Şekil 1). Pişirme işlemi sonrasında ürünler 200 ml'lik metal kapaklı cam kavanozlara sıcak olarak doldurulmuş ve kavanozların ağızları metal twist-off kapakları ile hermetikli olarak kapatilip kavanozlar ters çevrilmiş ve 10 dakika kadar bu şekilde bekletildikten sonra kavanozlar normal pozisyonuna çevrilmiştir. Kavanozlar kademeli olarak yaklaşı1 $30{ }^{\circ} \mathrm{C}^{\prime}$ ye kadar soğutulmuş ve analiz yapıllnncaya kadar oda sicaklığında karanlık bir yerde muhafaza edilmiştir. Çalışmada her uygulama 2 tekerrürlü olarak gerçekleştirilmiştir (Kaya ve ark., 2016) (Şekil 2).
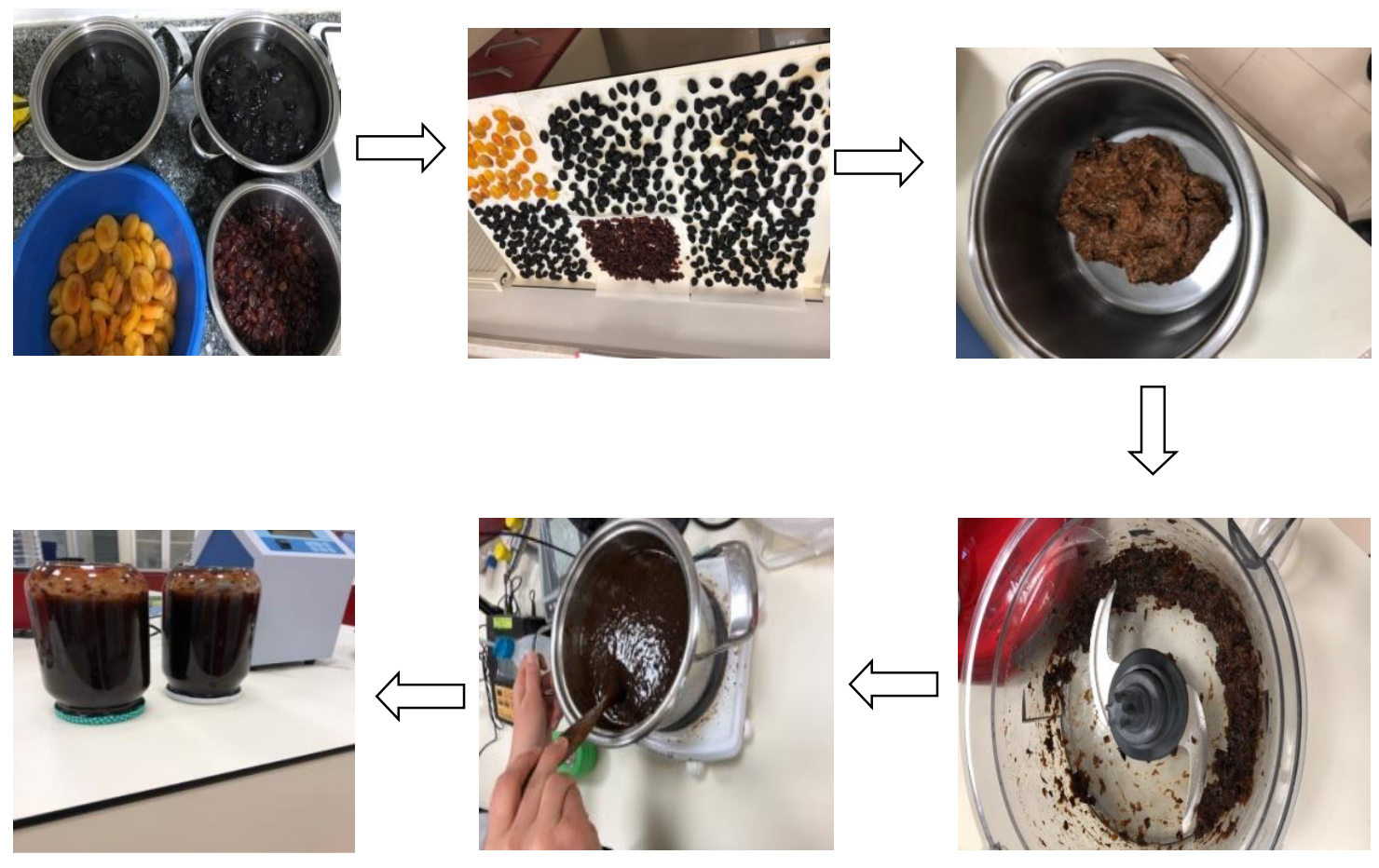

Şekil 1. Yalın ve Karışık Meyveli Erik Marmelatı Üretimi 


\section{Hammadde Temini}

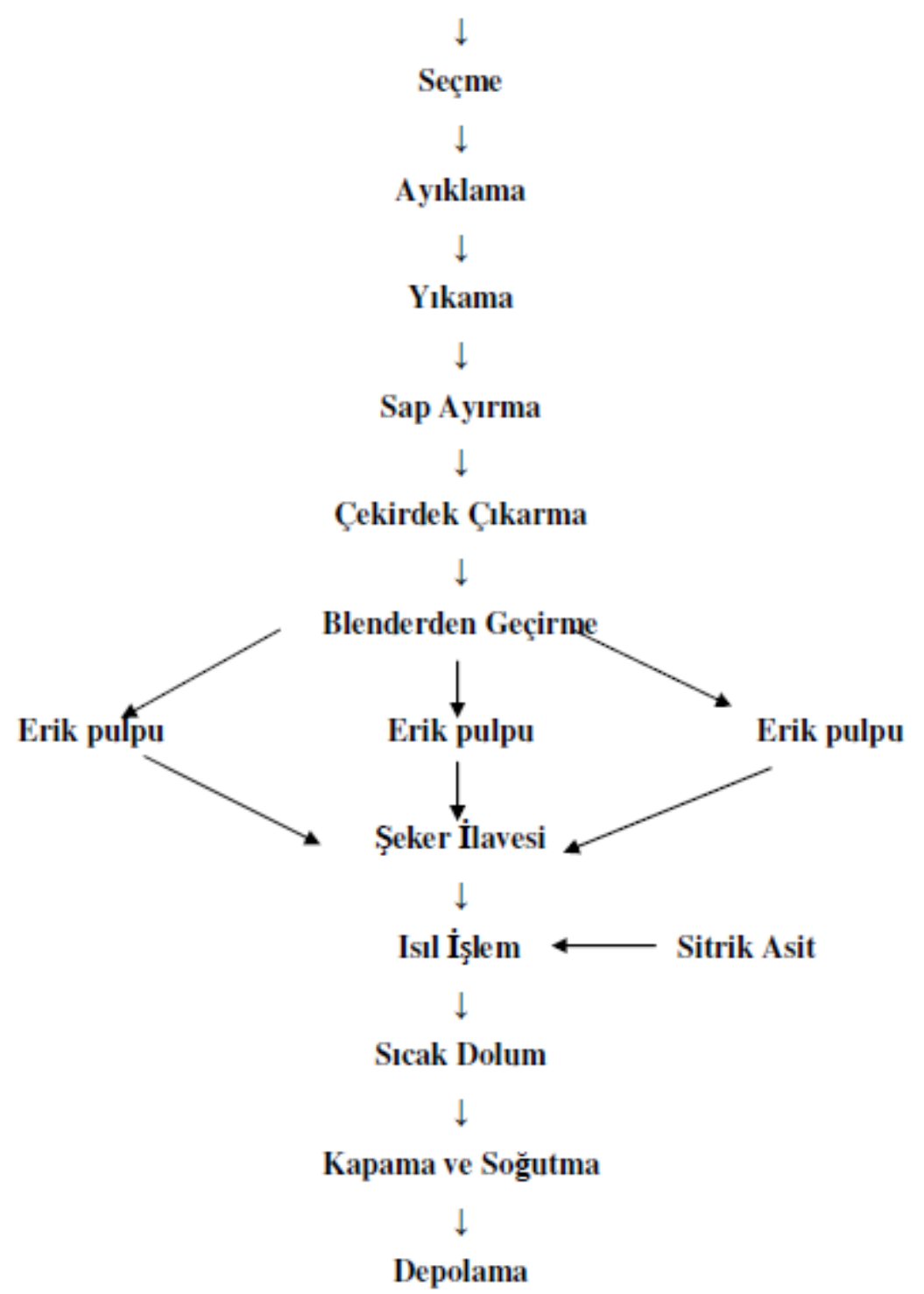

Şekil 2. Yalın ve Karışık Meyveli Erik Marmelatı Üretimi Akış Şeması

\section{Uygulanan Analizler \\ Pomolojik analizler}

Tesadüfi olarak alınan 10 adet eriğin en ve boy ölçümleri, Inox marka kumpas yardımı ile yapılmış ve ortalama değerler " $\mathrm{mm}$ " olarak belirtilmiştir. Tesadüfi olarak alınan 10 adet eriğin ağırlık ölçümleri, 0.01 grama duyarlı elektronik terazi (ATX224, Shimadzu, Japan) ile yapılmış ve ortalama sonuçlar gram olarak belirtilmiştir. Tesadüfi olarak alınan 10 adet eriğin çıkartılan çekirdekleri tartılmış ve ortalama sonuçlar gram olarak verilmiştir.

\section{Fizikokimyasal analizler}

$\mathrm{pH}$ değerleri cam elektrotlu ISOLAB marka $\mathrm{pH}$ metre kullanılarak ölçülmüsstür (Cemeroğlu, 2007). Titrasyon asitliği tayini Sanchez-Moreno (2003) tarafından verilen yönteme göre yapılmış ve sonuçlar, sitrik asit cinsinden $\mathrm{g} / 100 \mathrm{~g}$ olacak șekilde hesaplanmıștır. Suda çözünür kuru madde 
miktar1 masa tipi el refraktometresi (Milwaukee MA871 Refractometer) ile $+20^{\circ} \mathrm{C}^{\prime}$ de belirlenmiştir. Sonuçlar \% olarak ifade edilmiştir (Cemeroğlu, 2007). Su aktivitesi ölçümü ölçüm cihaz1 (Novasina-Labtouch-aW) kullanilarak yapılmıştır. Kül miktarı tayininde, AACC (1999) tarafindan bildirilen metot kullanılmıştır. Örneklerin viskozitesi Fungilab Expert (Model L, Sant Feliu de Llobregat, Barcelona) marka vizkozimetre kullanilarak 100 rpm'de L4 spindle ile belirlenip cP olarak ifade edilmiştir.

\section{Diğer analizler}

Örneklerdeki toplam fenolik ve toplam flavanoid içerikleri ile antioksidan ve askorbik asit tayinleri Uçan Türkmen ve Mercimek Takc1 (2018) tarafindan verilen yöntemlere göre yapılmıştır. 5hidroksimetilfurfural (HMF) içeriği, kırmızı renkli bir kompleks oluşturan, barbitürik asit, p-toluidin ve HMF arasındaki kolorimetrik reaksiyona dayalı olarak Cemeroğlu (2007) tarafindan tarif edilen prosedür izlenerek tespit edilmiştir. İnvert şeker Mercimek Takc1 ve Uçan Türkmen (2016) tarafindan verilen yöntemle tayin edilmiştir. Renk (CIE L*, a*, b*) analizi, el tipi renk cihazı (HunterLab miniscan EZ, ABD) ile belirlenmiştir.
Buna ek olarak, Hue ve kroma değerleri aşağıdaki formüller baz alınarak kullanılmıştır:

$$
\begin{aligned}
& \text { Hue }=\arctan \left(\frac{b^{*}}{a^{*}}\right) \\
& C^{*}=\sqrt{\left(a^{*}\right)^{2}+\left(b^{*}\right)^{2}}
\end{aligned}
$$

13 kişilik panelist grubu tarafindan yapılan duyusal değerlendirmede marmelatlar "renk", "tat ve lezzet", "kivam", "koku" ve "genel izlenim" özellikleri bakımından değerlendirilmiştir (Watts ve ark., 1989; Altuğ, 1993). Örnekler arasındaki önemli farklilıkları saptamak amaciyla Windows SPSS 23.0 yazılımı (SPSS Inc., Chicago, IL, ABD) kullanilarak varyans analizi (ANOVA) ve Duncan çoklu karşılaştırma testi aracilı̆̆gyla istatistiksel analizler yapilmıştır. Her bir analiz üç tekerrürlü yapılmıştır.

\section{SONUÇ ve TARTIŞMA}

Erik (\%100), Erik (\%75)-Kayısı (\%25), Erik (\%75)-Yabanmersini (\%25), Erik (\%50)Kayis1 (\%25)-Yabanmersini (\%25) Pulplarının Özellikleri

Çizelge 1'de görüldüğü gibi marmelata işlenecek eriklerin ortalama en, boy, ağırlık ve çekirdek ağırlı̆ı değerleri sırası ile $5.25 \mathrm{~mm}, 4.60 \mathrm{~mm}$, $106.8 \mathrm{~g}$ ve $15.3 \mathrm{~g}$ olarak bulunmuştur.

Çizelge 1. Eriğin Pomolojik Özellikleri

Table 1. Pomological Characteristics of Plum

\begin{tabular}{lcccc}
\hline & $\begin{array}{c}\text { Eni } \\
\text { Widht }\end{array}$ & $\begin{array}{c}\text { Boyu } \\
\text { Lenght }\end{array}$ & $\begin{array}{c}\text { Ağırlığ1 } \\
\text { Weight }\end{array}$ & $\begin{array}{c}\text { Çekirdek Ağırllğ1 } \\
\text { Weight of Core }\end{array}$ \\
\hline $\begin{array}{l}\text { Erik } \\
\text { Plum }\end{array}$ & $5.25 \mathrm{~mm}$ & $4.60 \mathrm{~mm}$ & $106.8 \mathrm{~g}$ & $15.3 \mathrm{~g}$ \\
\hline
\end{tabular}

Çizelge 2'de görüldüğü gibi meyve pulp karışımlarının $\mathrm{pH}, \mathrm{SÇKM}$, titrasyon asitliği ve su aktivitesi değerleri arasındaki fark istatistiksel olarak önemli bulunmuştur $(P<0.05)$. Erik pulpunun $\mathrm{pH}$ değerleri 4.32 iken; diğer meyve pulpları ile hazırlanan örneklerin $\mathrm{pH}$ değerleri 3.99-4.41 arasında değişiklik göstermiştir. $\mathrm{pH}$ derecesi 3.5 derecenin altına düştükçe jelin kıvamı artmakta, jelde de bir katılaşma görülmektedir. pH'nın jel kıvamına etkisi, pektin ağını oluşturan liflerin belli $\mathrm{pH}$ sinırlarında esneklik kazanması şeklinde açılanmaktadır. Buna göre $\mathrm{pH}$ belirli sinırlar arasındayken pektin lifleri maksimum esneklik kazanmakta ve iyi bir jel oluşturmaktadır
(Cemeroğlu ve ark., 2003). SÇKM değerleri yalın erik pulpunda $\% 38.8$ iken diğerlerinde \%33.6-38.3 arasında bulunmuştur (Çizelge 2). Titrasyon asitliği değerleri yalın erik pulpunda 8.87 $\mathrm{g} / 100 \mathrm{~mL}$ iken karışımlarda 7.54-9.00 g/100mL arasında değişmiştir (Çizelge 2). Pulp örneklerinin viskozite değerleri 4827.50-4851.50 $\mathrm{cP}$ aralığında tespit edilmiştir (Çizelge 2) $(P>0.05)$. Su aktivitesi $\left(a_{w}\right)$ yalın erik pulpunda 0.928 iken diğerlerinde 0.938-0.944 arasinda bulunmuştur (Çizelge 2). Atıc1 (2013), çalışmasında taze erik örneklerinin ortalama su aktivitesi değerlerini 0.919, katk1l pulp ve katkısız pulp örneklerinin ortalama su aktivite değerlerini ise sirasiyla 0.907 ve 0.953 
olarak belirlenmiştir. Ayrıca araştırmacı, katkılı pulp örneklerinin, kontrol pulp örneklerine ve hammaddeye göre su aktivitesi değerlerinin daha düşük bulunmasının sebebinin şekerin yapısında bulunan serbest suyu bağlamasindan kaynaklanabileceğini bildirmiştir. Erik pulpunun kül değeri \%0.91 iken, diğer meyve pulplan ile hazırlanan örneklerin kül değerleri \%0.74-1.105 arasında değişiklik göstermiştir (Çizelge 2). Meyve pulp karışımlarının kül içerikleri arasındaki fark istatistiksel olarak önemsiz bulunmuştur $(P>0.05)$. Genel anlamda suda çözünür kuru madde değeri yüksek olan pulpların kül değerleri yüksek bulunurken, düşük değere sahip olan pulpların kül değerleri de düşük bulunmuştur.

Çizelge 2. Marmelat Üretiminde Kullanılan Pulpların Fizikokimyasal Özellikleri Table 2. Physicochemical properties of pulps used in production of marmalade

\begin{tabular}{|c|c|c|c|c|c|c|}
\hline $\begin{array}{l}\text { Örnekler } \\
\text { Samples }\end{array}$ & $\begin{array}{l}\mathrm{pH} \\
p H\end{array}$ & $\begin{array}{c}\text { Suda Çözünür } \\
\text { Kuru Madde } \\
\text { ( }{ }^{\circ} \text { Briks) } \\
\text { Total soluble solids } \\
\text { (TSS) } \\
\left({ }^{\circ} \text { Brix) }\right.\end{array}$ & $\begin{array}{c}\text { Titrasyon } \\
\text { Asitliği } \\
\text { (g/100 mL) } \\
\text { Titratable acidity } \\
\text { (g/100 mL) }\end{array}$ & $\begin{array}{l}\text { Su Aktivitesi }\left(\mathrm{a}_{\mathrm{w}}\right) \\
\text { Water activity }\left(a_{w}\right)\end{array}$ & $\begin{array}{l}\text { Kül (\%) } \\
\text { Ash (\%) }\end{array}$ & $\begin{array}{l}\text { Viskozite } \\
\text { (cP) } \\
\text { Viscosity } \\
\text { (cP) }\end{array}$ \\
\hline $\begin{array}{l}\text { Erik (\%100) } \\
\text { Plum (\%100) }\end{array}$ & $4.32 \pm 0.00^{\mathrm{b}}$ & $38.8 \pm 0.35^{\mathrm{a}}$ & $8.87 \pm 0.39^{a}$ & $0.928 \pm 0.928^{c}$ & $0.91 \pm 0.05^{\mathrm{ab}}$ & $4827.00 \pm 5.0^{\mathrm{a}}$ \\
\hline $\begin{array}{l}\text { Erik(\%75)- } \\
\text { Kay1s1(\%25) } \\
\text { Plum }(\% 100) \\
\text { Apricot }(\% 25)\end{array}$ & $4.41 \pm 0.01^{\mathrm{a}}$ & $36.7 \pm 0.30^{\mathrm{b}}$ & $9.00 \pm 0.03^{\mathrm{a}}$ & $0.940 \pm 0.941^{\mathrm{a}}$ & $0.86 \pm 0.20^{\mathrm{ab}}$ & $4839.00 \pm 0.00^{a}$ \\
\hline $\begin{array}{l}\text { Erik(\%75)- } \\
\text { Yabanmersini(\%25) } \\
\text { Plum(\%75)- } \\
\text { Blueberry }(\% 25)\end{array}$ & $3.99 \pm 0.01^{\mathrm{d}}$ & $33.6 \pm 0.36^{c}$ & $7.54 \pm 0.03^{\mathrm{b}}$ & $0.944 \pm 0.944^{\mathrm{a}}$ & $0.74 \pm 0.00^{\mathrm{b}}$ & $4851.50 \pm 16.5^{a}$ \\
\hline $\begin{array}{l}\text { Erik }(\% 50)- \\
\text { Kay1sı (\%25)- } \\
\text { Yabanmersini (\%25) } \\
\text { Plum }(\% 50) \text { - } \\
\text { Apricot }(\% 25) \\
\text { Blueberry }(\% 25)\end{array}$ & $4.21 \pm 0.00^{c}$ & $38.3 \pm 0.00^{\mathrm{a}}$ & $7.63 \pm 0.03^{\mathrm{b}}$ & $0.938 \pm 0.938^{b}$ & $1.105 \pm 0.14^{\mathrm{a}}$ & $4849.50 \pm 9.5^{\mathrm{a}}$ \\
\hline
\end{tabular}

*Sütunlarda farklı küçük harfler ile gösterilen örnekler arasındaki farklılıklar 0.05 düzeyinde önemlidir.

Differences between the examples shown in columns with different lowercase letters are important at 0.05 level.

Meyve pulp karışımlarının $L^{*}, a^{*}, b^{*}$ ve invert şeker değerleri arasındaki fark istatistiksel olarak önemli bulunmuştur $(P<0.05)$ (Çizelge 3). Renk ölçümü esnasinda " $L$ ", “a*" ve "b*" değerleri elde edilmiş olup, "L" değeri parlaklıktan koyuluğa, "+ a*” kırmızılı̆̆a, “- a " yeşilliğe, “+ $\mathrm{b}^{*}$ ” sarlliğa ve “- $\mathrm{b}^{*}$ ” ise maviliğe gidişi göstermektedir (Gould, 1977). En düşük L* değeri (0.42) yalın erik pulpunda, en yüksek $L^{*}$ değeri (2.03) ise erik-kayısı pulp karışımında tespit edilmiştir. Erik pulpuna kayısı katıldığında, L* değerinde artış gözlenmiş, kayısı miktarı arttıkça $\mathrm{L}^{*}$ değeri artmıştır. Antosiyanin içeren meyve ve sebze ürünlerinin rengi, çeşitli etkenlerle antosiyaninlerin parçalanması sonucu değişmektedir. Bu hususta sıcaklık, askorbik asit, şekerler ve parçalanma ürünleri, hatta enzimler, oksijen, 1şık gibi birçok faktör rol oynamaktadır (Cemeroğlu, 2004). Meyve pulplarının $\mathrm{a}^{*}$ (+kırmızı,-yeşil) değerleri 2.82-10.81 arasında değişim göstermiştir (Çizelge 3 ). En yüksek a* değeri erik-kayısı pulpunda tespit edilmiştir. Aynı 
zamanda pulp karışımında kayısı-erik pulpu oranı azalıp, yabanmersini veya erik pulpu oranı arttıkça, $a^{*}$ değerinde de azalma görülmüştür. Bu sonuç üzerinde meyve et renklerine ilaveten, pulp işlemleri sirasinda yabanmersini ve eriğin okside olarak renklerinin koyulaşmasının da etkisinin olduğu düşünülmektedir. Meyve pulp karışımlarında en yüksek b* (+sarı,-mavi) değeri erik-kayısı pulp karışımında 3.50 olarak tespit edilmiştir (Çizelge 3). En yüksek Hue ve Kroma değerleri \%25 kayısı katkılı marmelattan elde edilmiştir. İnvert şeker değeri yalın erik pulpunda $58.672 \mu \mathrm{mol} / \mathrm{mL}$ iken diğer pulp karışımlarında 64.358-65.339 $\mu \mathrm{mol} / \mathrm{mL}$ arasında değişiklik göstermiştir (Çizelge 3).

Çizelge 3. Marmelat Üretiminde Kullanılan Pulpların Renk ve İnvert Şeker Değerleri Table 3. Color and invert sugar values of pulps used in production of marmalade

\begin{tabular}{|c|c|c|c|c|c|c|}
\hline $\begin{array}{l}\text { Örnekler } \\
\text { Samples }\end{array}$ & $\begin{array}{l}L^{*} \\
L^{*}\end{array}$ & $\begin{array}{l}a^{*} \\
a^{*}\end{array}$ & $\begin{array}{l}\mathrm{b}^{*} \\
b^{*}\end{array}$ & $\begin{array}{l}\text { Hue } \\
\text { Hue }\end{array}$ & $\begin{array}{l}\text { Kroma } \\
\text { Chroma }\end{array}$ & $\begin{array}{l}\text { Invert Şeker } \\
(\mu \mathrm{mol} / \mathrm{mL}) \\
\text { Invert sugar } \\
(\mu \mathrm{mol} / \mathrm{mL})\end{array}$ \\
\hline $\begin{array}{l}\text { Erik }(\% 100) \\
\text { Plum }(\% 100)\end{array}$ & $0.42 \pm 0.002^{\mathrm{d}}$ & $2.82 \pm 0.12^{\mathrm{d}}$ & $0.72 \pm 0.04^{\mathrm{d}}$ & $14.44 \pm 0.10^{c}$ & $2.91 \pm 0.12^{\mathrm{d}}$ & $58.672 \pm 1.740^{b}$ \\
\hline $\begin{array}{l}\text { Erik }(\% 75)- \\
\text { Kay1s1(\%25) } \\
\text { Plum }(\% 100) \\
\text { Apricot }(\% 25)\end{array}$ & $2.03 \pm 0.12^{\mathrm{a}}$ & $10.81 \pm 0.03^{a}$ & $3.50 \pm 0.21^{\mathrm{a}}$ & $17.94 \pm 0.96^{\mathrm{a}}$ & $11.36 \pm 0.09^{a}$ & $65.339 \pm 0.704^{2}$ \\
\hline $\begin{array}{l}\text { Erik }(\% 75)- \\
\text { Yabanmersini }(\% 25) \\
\text { Plum }(\% 75)- \\
\text { Blueberry }(\% 25)\end{array}$ & $1.12 \pm 0.00^{c}$ & $7.06 \pm 0.03^{c}$ & $1.94 \pm 0.02^{\mathrm{c}}$ & $15.32 \pm 0.04^{\mathrm{bc}}$ & $7.33 \pm 0.04^{c}$ & $65.123 \pm 2.016^{\mathrm{a}}$ \\
\hline $\begin{array}{l}\text { Erik }(\% 50)- \\
\text { Kay1s1 }(\% 25)- \\
\text { Yabanmersini (\%25) } \\
\text { Plum }(\% 50) \text { - } \\
\text { Apricot }(\% 25) \\
\text { Blueberry }(\% 25)\end{array}$ & $1.60 \pm 0.23^{\mathrm{b}}$ & $9.60 \pm 1.24^{b}$ & $2.76 \pm 0.39^{\mathrm{b}}$ & $16.05 \pm 0.15^{b}$ & $10.00 \pm 1.30^{\mathrm{b}}$ & $64.358 \pm 1.783$ \\
\hline
\end{tabular}

*Sütunlarda farklı küçük harfler ile gösterilen örnekler arasındaki farklılıklar 0.05 düzeyinde önemlidir.

Differences between the examples shown in columns with different lowercase letters are important at 0.05 level.

Toplam fenolik madde miktarı değeri yalın erik pulpunda $2.10 \mathrm{mg} \mathrm{GAE} / \mathrm{g}$ iken diğer pulplarda 1.71-2.12 $\mathrm{mg}$ GAE/g arasında değişiklik göstermiştir $(P<0.05)$ (Çizelge 4$)$. Kaya ve ark. (2016), çalışmasında kayısı pulpunun toplam fenolik madde miktarını ortalama $111.56 \mathrm{mg}$ GAE/kg olarak belirlemişlerdir. Erik pulpunun toplam flavonoid madde miktarı değeri $0.010 \mathrm{mg}$ $\mathrm{RE} / \mathrm{kg}$ iken, diğer pulplarda 0.007-0.009 mg $\mathrm{RE} / \mathrm{kg}$ arasında değişmiştir (Çizelge 4). Meyve pulp karışımlarının toplam flavonoid madde miktarı değerleri arasındaki fark istatistiksel olarak önemsiz bulunmuştur $(P>0.05)$. Pulp örneklerinin antioksidan aktivite değerleri \%58.98-79.49 arasında değişiklik göstermiştir $(P<0.05)$. Antioksidan aktivite değeri en yüksek marmelatın erik-kayısı marmelatı olduğu tespit edilmiştir (Çizelge 4). En düşük değerler erik-kayıs1yabanmersini karışımlarında görülmüştür. Atıcı (2013), çalışmasında erik örneklerinin ortalama antioksidan aktivite değerlerini \%66.77, katk1lı pulp örneklerinin \%65.03, kontrol pulp örneklerinin ise \%65.38 olarak belirlemiştir (Çizelge 4). Yalın erik pulpunun askorbik asit değeri $49.04 \mathrm{mg} / \mathrm{L}$ iken, diğer pulpların askorbik asit değerleri $49.55-50.90 \mathrm{mg} / \mathrm{L}$ arasinda değişiklik göstermiştir (Çizelge 4$)(P>0.05)$. 
Çizelge 4. Marmelat Üretiminde Kullanılan Pulpların Toplam Fenolik Madde, Toplam Flavonoid Madde, Antioksidan Aktivite ve Askorbik Asit Değerleri

Table 4. Total phenolic matter, total flavonoid matter, antioxidant activity and ascorbic acid values of pulps used in production of marmalade

\begin{tabular}{|c|c|c|c|c|}
\hline $\begin{array}{l}\text { Örnekler } \\
\text { Samples }\end{array}$ & $\begin{array}{l}\text { Toplam Fenolik } \\
\text { (mg GAE/g) } \\
\text { Total phenolics } \\
\text { (mg GAE/g) }\end{array}$ & $\begin{array}{c}\text { Toplam } \\
\text { Flavonoid } \\
\text { (mg RE/kg) } \\
\text { Total flavonoids (mg } \\
\text { RE/ } / \mathrm{kg} \text { ) }\end{array}$ & $\begin{array}{l}\text { Antioksidan } \\
\text { Aktivite (\%) } \\
\text { Antioxidant } \\
\text { activity (\%) }\end{array}$ & $\begin{array}{l}\text { Askorbik Asit } \\
\text { (mg/L) } \\
\text { Ascorbic acid } \\
(\mathrm{mg} / \mathrm{L})\end{array}$ \\
\hline $\begin{array}{l}\text { Erik (\%100) } \\
\text { Plum (\%100) }\end{array}$ & $2.10 \pm 0.10^{\mathrm{a}}$ & $0.010 \pm 0.00^{\mathrm{a}}$ & $72.14 \pm 1.66^{\mathrm{b}}$ & $49.04 \pm 0.96^{\mathrm{b}}$ \\
\hline $\begin{array}{l}\text { Erik }(\% 75)- \\
\text { Kayis1 }(\% 25) \\
\text { Plum } \% 100) \\
\text { Apricot }(\% 25)\end{array}$ & $2.12 \pm 0.02^{\mathrm{a}}$ & $0.009 \pm 0.00^{\mathrm{ab}}$ & $79.49 \pm 4.85^{\mathrm{a}}$ & $49.55 \pm 0.11^{\mathrm{ab}}$ \\
\hline $\begin{array}{l}\text { Erik(\%75)- } \\
\text { Yabanmersini }(\% 25) \\
\text { Plum(\%75)- } \\
\text { Blueberry(\%25) }\end{array}$ & $1.74 \pm 0.04^{\mathrm{b}}$ & $0.009 \pm 0.00^{\mathrm{ab}}$ & $64.53 \pm 2.22^{c}$ & $50.90 \pm 1.31^{a}$ \\
\hline $\begin{array}{l}\text { Erik }(\% 50)- \\
\text { Kay1s1 }(\% 25)- \\
\text { Yabanmersini (\%25) } \\
\text { Plum }(\% 50)- \\
\text { Apricot }(\% 25) \\
\text { Blueberry }(\% 25)\end{array}$ & $1.71 \pm 0.02^{\mathrm{b}}$ & $0.007 \pm 0.00^{\mathrm{b}}$ & $58.98 \pm 5.46^{c}$ & $49.81 \pm 0.58^{\mathrm{ab}}$ \\
\hline
\end{tabular}

*Sütunlarda farklı küçük harfler ile gösterilen örnekler arasındaki farkl1lıklar 0.05 düzeyinde önemlidir.

Differences between the examples shown in columns with different lowercase letters are important at 0.05 level.

Erik (\%100), Erik (\%75)-Kay1s1 (\%25), Erik (\%75)-Yabanmersini (\%25), Erik (\%50)Kayisi (\%25)-Yabanmersini (\%25) Marmelatlarının Özellikleri

Marmelat karışımlarının $\mathrm{pH}$, SÇKM, titrasyon asitliği, su aktivitesi ve kül değerleri arasındaki fark istatistiksel olarak önemli bulunmuştur $(P<0.05)$. Tüm marmelat örneklerinin $\mathrm{pH}$ değerleri 3.603.87 arasında değişiklik göstermiştir (Çizelge 5). Reçel, Jöle, Marmelat Tatlandırılmış Kestane Püresi Tebliği’nde gerekli $\mathrm{pH}$ derecesinin 2.8-3.5 olması belirtilmiştir. SÇKM değeri yalın erik marmelatında \%63.6, kay1s1 katk1lı marmelatta \%62.8, yabanmersini katk11 marmelatta \%62.8 iken kay1s1-yabanmersini katkilı marmelatta \%63.1'dir (Çizelge 5). Reçel, Jöle, Marmelat ve Tatlandırılmış Kestane Püresi Tebliğìnde geleneksel marmelatta refraktometre ile tayin edilen çözünebilir kuru madde içeriğinin \%55'den daha az olmaması gerektiği belirtilmiştir. Elde edilen sonuçlara göre marmelat örneklerinin suda çözünür kuru madde oranlarının tebliğe uygun olduğu görülmüştür. Marmelat örneklerinde titrasyon asitliği miktarları 11.60-17.41 g/100mL arasında değişiklik göstermiştir (Çizelge 5). Su aktivitesi $\left(\mathrm{a}_{\mathrm{w}}\right)$ yalın erik marmelatında 0.854 iken, diğerlerinde $0.858-0.862$ arasinda bulunmuştur (Çizelge 5) $(P<0.05)$. Marmelat örneklerinin viskozite değerleri $3874.50-4832.00 \mathrm{cP}$ aralığında tespit edilmiştir (Çizelge 5). En düşük kül içeriğinin $(\% 0.15)$ yabanmersini katkılı marmelatta, en yüksek kül içeriğinin ise (\%1.55) yalın erik marmelat örneklerinde olduğu belirlenmiştir (Çizelge 5) $(P<0.05)$. Reçel, Jöle, Marmelat ve Tatlandırılmış Kestane Püresi Tebliği’ne göre kül miktarının geleneksel marmelatta en çok $20 \mathrm{mg} / \mathrm{kg}$ olabileceği belirtilmiştir.

Marmelat karışımlarının $L^{*}, a^{*}, b^{*}$ ve invert şeker değerleri arasındaki fark istatistiksel olarak önemli bulunmuştur $(P<0.05) \quad$ (Çizelge 6$)$. Marmelat 
üretiminde $L^{*}$ değeri en düşük (1.02) kayısı katkılı marmelatta tespit edilirken, en yüksek (2.22) $\mathrm{L}^{*}$ değeri kay1s1-yabanmersini katkılı marmelatta tespit edilmiştir. $a^{*}$ değerleri 1.16-2.02 arasında değişiklik göstermiş̧ir. En yüksek b* değeri (2.28) erik-kayısi-yabanmersini marmelat karışımında tespit edilirken, en düşük $\mathrm{b}^{*}$ değeri (1.56) ise erikkayıs1 marmelat karışımlarında gözlemlenmiştir. En yüksek Hue değerleri yalın erik pulpu marmelatında, en yüksek kroma değerleri ise erik kayısı yaban mersini marmelat örneklerinden elde edilmiştir (Çizelge 6). HMF değerleri 82.08-93.96 $\mathrm{mg} / \mathrm{L}$ arasında değişiklik göstermiştir (Çizelge 6). En yüksek HMF $(93.96 \mathrm{mg} / \mathrm{L})$ yabanmersini katkılı erik bazlı geleneksel marmelatlarda görülürken, en düşük HMF $(82.08 \mathrm{mg} / \mathrm{L})$ miktarı kayıs1-yabanmersini katkılı erik bazlı geleneksel marmelatlarda tespit edilmiştir. Reçel, Jöle,
Marmelat ve Tatlandırılmış Kestane Püresi Tebliği'nde hidroksimetilfurfural (HMF) sinırlandırmasina rastlanmamaktadır. Ancak bazı reçel standartlarında 1. sinıf reçellerde bulunması gereken en yüksek HMF değeri $50 \mathrm{mg} / \mathrm{kg}$ olarak belirtilirken, ikinci sınıf reçeller için en yüksek HMF değeri $100 \mathrm{mg} / \mathrm{kg}$ olarak belirtilmiştir. Sonuç olarak bu tebliğe göre yaptığımız çalışmalardaki marmelat örneklerinin 2. sınıf kalitesinde olduğu belirlenmiştir. İnvert şeker değerleri $\quad 68.75-75.55 \mu \mathrm{mol} / \mathrm{mL}$ arasında değişiklik göstermiştir. En yüksek değere (75.556 $\mu \mathrm{mol} / \mathrm{mL}$ ) sahip olan örneğin erik-yabanmersini marmelatı karıșımına ait olduğu tespit edilmiştir (Çizelge 6). Yurdagül (2007), çalıșmasında erik marmelatı örneklerinde ortalama invert şeker değerlerinin \%19.56-21.89 arasında olduğunu tespit etmiştir.

Çizelge 5. Marmelat Örneklerinin Fizikokimyasal Özellikleri

Table 5. Physicochemical properties of marmelade samples

\begin{tabular}{|c|c|c|c|c|c|c|}
\hline $\begin{array}{l}\text { Örnekler } \\
\text { Samples }\end{array}$ & $\begin{array}{l}\mathrm{pH} \\
p H\end{array}$ & $\begin{array}{c}\text { Suda } \\
\text { Çözünür } \\
\text { Kuru } \\
\text { Madde } \\
\text { ( }{ }^{\circ} \text { Briks) } \\
\text { Total soluble } \\
\text { solids (TSS) } \\
\text { ( }{ }^{\circ} \text { Brix) } \\
\end{array}$ & $\begin{array}{l}\text { Titrasyon } \\
\text { Asitliği } \\
\text { (g/100 mL) } \\
\text { Titratable } \\
\text { acidity } \\
\text { (g/100 mL) }\end{array}$ & $\begin{array}{l}\text { Su Aktivitesi } \\
\qquad\left(a_{\mathrm{w}}\right) \\
\text { Water activity } \\
\left(a_{w}\right)\end{array}$ & $\begin{array}{l}\text { Kül (\%) } \\
\text { Ash (\%) }\end{array}$ & $\begin{array}{l}\text { Viskozite } \\
\quad(\mathrm{cP}) \\
\text { Viscosity } \\
(c P)\end{array}$ \\
\hline $\begin{array}{l}\text { Erik }(\% 100) \\
\text { Plum }(\% 100)\end{array}$ & $3.84 \pm 0.11^{\mathrm{a}}$ & $63.6 \pm 0.05^{\mathrm{a}}$ & $17.41 \pm 1.10^{\mathrm{a}}$ & $0.854 \pm 0.00^{c}$ & $1.55 \pm 0.10^{\mathrm{a}}$ & $4829.0 \pm 11.00^{a}$ \\
\hline $\begin{array}{l}\text { Erik }(\% 75)- \\
\text { Kay1s1(\%25) } \\
\text { Plum }(\% 100) \\
\text { Apricot }(\% 25)\end{array}$ & $3.87 \pm 0.06^{a}$ & $62.8 \pm 0.25^{c}$ & $11.60 \pm 0.32^{c}$ & $0.862 \pm 0.00^{\mathrm{a}}$ & $0.29 \pm 0.06^{\mathrm{b}}$ & $3874.5 \pm 33.5^{c}$ \\
\hline $\begin{array}{l}\text { Erik }(\% 75)- \\
\text { Yabanmersini }(\% 25) \\
\text { Plum }(\% 75) \text { - } \\
\text { Blueberry }(\% 25)\end{array}$ & $3.68 \pm 0.02^{\mathrm{b}}$ & $62.8 \pm 0.15^{b c}$ & $12.17 \pm 0.90^{\mathrm{bc}}$ & $0.862 \pm 0.00^{a}$ & $0.15 \pm 0.02^{c}$ & $4832.5 \pm 6.50^{a}$ \\
\hline $\begin{array}{l}\text { Erik }(\% 50)- \\
\text { Kay1s1 }(\% 25)- \\
\text { Yabanmersini (\%25) } \\
\text { Plum }(\% 50) \text { - } \\
\text { Apricot }(\% 25) \\
\text { Blueberry }(\% 25)\end{array}$ & $3.60 \pm 0.00^{\mathrm{b}}$ & $63.1 \pm 0.10^{\mathrm{a}}$ & $13.26 \pm 0.76^{\mathrm{b}}$ & $0.858 \pm 0.858^{b}$ & $0.17 \pm 0.07 \mathrm{bc}$ & $4449.0 \pm 78.00^{b}$ \\
\hline
\end{tabular}

*Sütunlarda farklı küçük harfler ile gösterilen örnekler arasındaki farklılıklar 0.05 düzeyinde önemlidir.

Differences between the examples shown in columns with different lowercase letters are important at 0.05 level. 
Çizelge 6. Marmelat Örneklerinin Renk, HMF ve İnvert Şeker Değerleri Table 6. Color, HMF and invert sugar values of marmelade samples

\begin{tabular}{|c|c|c|c|c|c|c|c|}
\hline $\begin{array}{l}\text { Örnekler } \\
\text { Samples }\end{array}$ & $\begin{array}{l}\mathrm{L}^{*} \\
L^{*}\end{array}$ & $\begin{array}{l}a^{*} \\
a^{*}\end{array}$ & $\begin{array}{l}\mathrm{b}^{*} \\
b^{*}\end{array}$ & $\begin{array}{l}\text { Hue } \\
\text { Hue }\end{array}$ & $\begin{array}{l}\text { Kroma } \\
\text { Chroma }\end{array}$ & $\begin{array}{l}\mathrm{HMF}(\mathrm{mg} / \mathrm{L}) \\
H M F(m g / L)\end{array}$ & $\begin{array}{c}\text { İnvert Şeker } \\
\text { Invert sugar } \\
(\mu m o l / m L)\end{array}$ \\
\hline $\begin{array}{l}\text { Erik }(\% 100) \\
\text { Plum }(\% 100)\end{array}$ & $1.78 \pm 0.08^{b}$ & $1.16 \pm 0.06^{\mathrm{c}}$ & $1.62 \pm 0.01^{b}$ & $54.30 \pm 1.35^{\mathrm{a}}$ & $2.00 \pm 0.05^{b}$ & $87.26 \pm 8.70^{\mathrm{a}}$ & $68.75 \pm 4.797 b$ \\
\hline $\begin{array}{l}\text { Erik(\%75)- } \\
\text { Kay1s1(\%25) } \\
\text { Plum }(\% 100) \\
\text { Apricot }(\% 25)\end{array}$ & $1.02 \pm 0.29 \mathrm{c}$ & $1.48 \pm 0.00^{\mathrm{b}}$ & $1.56 \pm 0.29 \mathrm{~b}$ & $45.96 \pm 5.57 \mathrm{~b}$ & $2.16 \pm 0.21^{b}$ & $83.97 \pm 16.13^{a}$ & $69.50 \pm 0.801^{b}$ \\
\hline $\begin{array}{l}\text { Erik(\%75)- } \\
\text { Yabanmersini(\%25) } \\
\text { Plum(\%75)- } \\
\text { Blueberry(\%25) }\end{array}$ & $2.13 \pm 0.00^{a}$ & $1.36 \pm 0.13^{\mathrm{b}}$ & $1.78 \pm 0.08^{b}$ & $52.76 \pm 1.49^{a}$ & $2.24 \pm 0.14^{b}$ & $93.96 \pm 11.18^{a}$ & $75.55 \pm 0.498^{a}$ \\
\hline $\begin{array}{l}\text { Erik }(\% 50)- \\
\text { Kay1s1 }(\% 25)- \\
\text { Yabanmersini (\%25) } \\
\text { Plum }(\% 50) \text { - } \\
\text { Apricot }(\% 25) \\
\text { Blueberry }(\% 25)\end{array}$ & $2.22 \pm 0.16^{\mathrm{a}}$ & $2.02 \pm 0.08^{\mathrm{a}}$ & $2.28 \pm 0.05^{\mathrm{a}}$ & $48.53 \pm 1.81^{\mathrm{ab}}$ & $3.05 \pm 0.01^{\mathrm{a}}$ & $82.08 \pm 10.15^{a}$ & $73.96 \pm 2.714^{\mathrm{ab}}$ \\
\hline
\end{tabular}

*Sütunlarda farklı küçük harfler ile gösterilen örnekler arasındaki farklılıklar 0.05 düzeyinde önemlidir.

Differences between the examples shown in columns with different lowercase letters are important at 0.05 level.

Marmelat örneklerinin toplam fenolik ve toplam flavonoid madde miktarları ile antioksidan aktivite ve viskozite değerleri arasındaki fark istatistiksel olarak önemli bulunmuștur $(P<0.05)$. Marmelat örneklerinin toplam fenolik madde miktarı değerlerinin 3.26-3.91 mg GAE/g arasında olduğu belirlenmiştir (Çizelge 7). Yalın erik marmelat değeri $3.36 \mathrm{mgGAE} / \mathrm{g}$ olarak tespit edilmiştir. Yalın erik, erik-kayısı ve erikyabanmersini marmelatlarının toplam flavonoid madde miktarı değerleri $0.011 \mathrm{mgRE} / \mathrm{kg}$ iken erik-kayısi-yabanmersini marmelat karışımlarının değeri $0.010 \mathrm{mgRE} / \mathrm{kg}$ olarak tespit edilmiştir (Çizelge 7). Marmelat örneklerinin antioksidan aktivite değerlerinin \%58.73-73.04 arasında olduğu tespit edilmiştir (Çizelge 7). Yalın erik marmelat değeri \%66.54 iken en yüksek antioksidan değeri 73.04 ile erik-kayısı karışımı, en düşük antioksidan değeri ise $\% 58.73$ ile erikkayısı-yabanmersini karışımlarında tespit edilmiştir. Yalın erik marmelatın askorbik değeri $49.62 \mathrm{mg} / \mathrm{L}$ iken diğer marmelat karışımlarının değerleri 50.64-51.92 mg/L arasında değişiklik göstermişlerdir $(P>0.05)$ (Çizelge 7$)$. Marmelat karışımlarının duyusal analiz sonuçları arasındaki fark istatistiksel olarak önemli bulunmuştur $(P<0.05)$. (Çizelge 8). Duyusal değerlendirmede örneklerin kazanmış olduğu puanlar dikkate alındığında en çok beğenilen marmelatın 4.46 puan ile erik pulpundan üretilen örnek olduğu ve bunu azalan puan sirasina göre erik-kayısiyabanmersini, erik-kay1s1, erik yabanmersini pulplarından üretilen örneklerin takip ettiği belirlenmiştir.

\section{ÖNERİLER}

Araştırmadan elde edilen bulgular, ülkemizde sadece sofralık olarak tüketilen erik meyvesinin ürüne işlenip, alternatif tüketime katkı sağlayarak endüstriyel anlamda değer kazandırılabileceği durumunu ortaya çıkartmıştır. Isıl işlem ve diğer birçok proses, gıdaların kalite parametreleri üzerine etkili faktörlerdendir. Gidaların sahip oldukları bazı besin öğeleri bu gibi proseslerden fazlaca etkilenmekte ve bu da gidalarn besin değerlerinin azalmasına neden olmaktadır. Günümüzde daha çok geleneksel olarak üretilen marmelatların işleme şartlarının (1sıl işlem derecesi ve süresi) iyileştirilmesi, böylece biyoaktif bileşenler ve diğer besin öğelerinin marmelat üretimi esnasında mümkün olduğunca az zarar görmesinin veya optimum düzeyde korunmasının sağlanması ile mümkün olabilir. 
Çizelge 7. Marmelat Örneklerinin Toplam Fenolik Madde, Toplam Flavonoid Madde, Antioksidan Aktivite ve Askorbik Asit Değerleri

Table 7. Total phenolics, total flavonoids, antioxidant activity and ascorbic acid values of marmelade samples

\begin{tabular}{|c|c|c|c|c|}
\hline $\begin{array}{l}\text { Örnekler } \\
\text { Samples }\end{array}$ & $\begin{array}{l}\text { Toplam Fenolik } \\
\text { (mg GAE/g) } \\
\text { Total phenolics } \\
\text { (mg GAE/g) }\end{array}$ & $\begin{array}{l}\text { Toplam Flavonoid } \\
\text { (mg RE/kg) } \\
\text { Total flavonoids } \\
\text { (mg RE/ kg) }\end{array}$ & $\begin{array}{c}\text { Antioksidan } \\
\text { Aktivite (\%) } \\
\text { Antioxidant activity } \\
(\%) \\
\end{array}$ & $\begin{array}{c}\text { Askorbik Asit } \\
(\mathrm{mg} / \mathrm{L}) \\
\text { Ascorbic acid (mg/L) }\end{array}$ \\
\hline $\begin{array}{l}\text { Erik (\%100) } \\
\text { Plum }(\% 100)\end{array}$ & $3.36 \pm 0.14^{b}$ & $0.011 \pm 0.00^{\mathrm{a}}$ & $66.54 \pm 2.06^{\mathrm{b}}$ & $49.62 \pm 0.51^{b}$ \\
\hline $\begin{array}{l}\text { Erik }(\% 75)- \\
\text { Kay1s1(\%25) } \\
\text { Plum }(\% 100) \\
\text { Apricot }(\% 25)\end{array}$ & $3.91 \pm 0.17^{\mathrm{a}}$ & $0.011 \pm 0.00^{\mathrm{a}}$ & $73.04 \pm 1.91^{\mathrm{a}}$ & $50.64 \pm 1.49^{a b}$ \\
\hline $\begin{array}{l}\text { Erik }(\% 75) \text { - } \\
\text { Yabanmersini(\%25) } \\
\text { Plum(\%75)- } \\
\text { Blueberry }(\% 25)\end{array}$ & $3.76 \pm 0.14^{\mathrm{a}}$ & $0.011 \pm 0.00^{\mathrm{a}}$ & $69.69 \pm 0.88^{\mathrm{ab}}$ & $51.79 \pm 0.89^{a}$ \\
\hline $\begin{array}{l}\text { Erik }(\% 50)- \\
\text { Kay1s1 }(\% 25)- \\
\text { Yabanmersini (\%25) } \\
\text { Plum }(\% 50) \text { - } \\
\text { Apricot }(\% 25) \\
\text { Blueberry }(\% 25)\end{array}$ & $3.26 \pm 0.21^{\mathrm{a}}$ & $0.010 \pm 0.00^{\mathrm{a}}$ & $58.73 \pm 4.52^{c}$ & $51.92 \pm 1.02^{\mathrm{a}}$ \\
\hline
\end{tabular}

*Sütunlarda farklı küçük harfler ile gösterilen örnekler arasındaki farklılıklar 0.05 düzeyinde önemlidir.

Differences between the examples shown in columns with different lowercase letters are important at 0.05 level.

Çizelge 8. Erik Bazlı Geleneksel Marmelat Örneklerinin Duyusal Analiz Değerleri Table 8. Sensory analysis values of tradational marmalade based plum

\begin{tabular}{|c|c|c|c|c|c|}
\hline \multirow[b]{2}{*}{$\begin{array}{l}\text { Örnekler } \\
\text { Samples }\end{array}$} & \multicolumn{5}{|c|}{$\begin{array}{l}\text { Duyusal Özellikler } \\
\text { Sensory properties }\end{array}$} \\
\hline & $\begin{array}{l}\text { Renk } \\
\text { Color }\end{array}$ & $\begin{array}{l}\text { Kivam } \\
\text { Consistency }\end{array}$ & $\begin{array}{r}\text { Koku } \\
\text { Smell }\end{array}$ & $\begin{array}{l}\text { Tat ve Lezzet } \\
\text { Taste and flavor }\end{array}$ & $\begin{array}{l}\text { Genel İzlenim } \\
\text { General impression }\end{array}$ \\
\hline $\begin{array}{l}\text { Erik }(\% 100) \\
\text { Plum }(\% 100)\end{array}$ & $4.31 \pm 0.85^{\mathrm{a}}$ & $4.54 \pm 0.66^{\mathrm{a}}$ & $3.31 \pm 1.32^{\mathrm{b}}$ & $4.38 \pm 0.77^{a}$ & $4.46 \pm 0.52^{\mathrm{a}}$ \\
\hline $\begin{array}{l}\text { Erik }(\% 75)-\text { Kay1si }(\% 25) \\
\text { Plum }(\% 100) \\
\text { Apricot }(\% 25)\end{array}$ & $4.46 \pm 0.8^{\mathrm{a}}$ & $4.46 \pm 0.66^{\mathrm{a}}$ & $3.19 \pm 1.22^{\mathrm{b}}$ & $4.12 \pm 0.92^{\mathrm{a}}$ & $4.08 \pm 0.86^{\mathrm{a}}$ \\
\hline $\begin{array}{l}\text { Erik }(\% 75) \text { - } \\
\text { Yabanmersini }(\% 25) \\
\text { Plum }(\% 75)- \\
\text { Blueberry }(\% 25)\end{array}$ & $4.23 \pm 0.83^{\mathrm{a}}$ & $4.62 \pm 0.51^{\mathrm{a}}$ & $3.31 \pm 1.25^{b}$ & $3.81 \pm 1.18^{\mathrm{ab}}$ & $4.08 \pm 1.06^{\mathrm{ab}}$ \\
\hline $\begin{array}{l}\text { Erik }(\% 50)-\text { Kay1s1 }(\% 25) \text { - } \\
\text { Yabanmersini }(\% 25) \\
\text { Plum }(\% 50) \text { - } \\
\text { Apricot }(\% 25) \\
\text { Blueberry }(\% 25)\end{array}$ & $4.54 \pm 0.88^{a}$ & $4.69 \pm 0.48^{a}$ & $3.31 \pm 1.11^{b}$ & $4.15 \pm 1.14^{\mathrm{a}}$ & $4.27 \pm 1.13^{\mathrm{a}}$ \\
\hline
\end{tabular}




\section{TEŞEKKÜR}

$\mathrm{Bu}$ çalısmanın gerçekleştirilmesinde laboratuvar olanaklarından yararlandığımız Kilis 7 Aralık Üniversitesi’ne ve Gıda Mühendisliği Bölümü’ne teşekkür ederiz.

\section{KAYNAKLAR}

AACC International (1999). Approved Methods of Analysis. Methods 08-01.01, 44- 19.01, 5440.02 and 76-31.01. Approved November 3, 1999, eleventh ed. Am Assoc Cereal Chem International, St. Paul, MN, USA.

Altuğ, T. (1993). Duyusal Test Teknikleri, Ege Üniversitesi Mühendislik Fakültesi. Ders Kitaplar1 Yayin No: 28, İzmir, 55s.

Anonymous. http://www.lezzet.com.tr/puf_noktalari/00990/ Erişim Tarihi:11.02.2019

Anonymous.

(2005b). http://www.gap.gov.tr/Turkish/Tarim/Meyveyt /erik.html Erişim Tarihi:11.02.2019.

Anonymous. (2005c). http://www.ziraatci.com.tr Erişim Tarihi:16.02.2019

Anonymous. (2006). Türk Gıda Kodeksi Reçel, Jöle, Marmelat ve Tatlandırılmış Kestane Püresi Tebliği, Tebliğ No: 2006/55. Resmi Gazete tarih ve sayisi: $\quad 30.12 .200626392$.

Atıc1, G. (2013). Erik Pestilinin Kalite Parametreleri ve Kuruma Davranışları Üzerine 'Sicak Havalı Kurutma ve Mikrodalga Kurutma' Yöntemlerinin Etkisinin Belirlenmesi Üzerine Bir Araştırma. Yüksek Lisans Tezi. Çukurova Üniversitesi, 108s., Adana.

Cemeroğlu, B., Karadeniz, F., Özkan, M. (2003). Meyve ve Sebze İşleme Teknolojisi. Gıda Teknolojisi Derneği Yayın No:28, (2), 690s, Ankara

Cemeroğlu, B. (2004). Meyve ve Sebze İşletme Teknolojisi. Cilt 1. Kültür ve Turizm Bakanllğ1 Yayınları, Ankara, 480s.

Cemeroğlu, B. (2007). Gıda analizleri. Kültür ve Turizm Bakanlığı Yayınları, s.167-172.
Çelik, H. (2006). Karadeniz Bölgesi İçin Yeni Bir Meyve Türü Yaban Mersini (Likapa), II. Ulusal Üzümsü Meyveler Sempozyumu, Eylül, Tokat, Bildiriler kitabi: 124-128.

Gould, A. W. (1977). Food Quality Assurence, The AVI publishing Company Inc. USA, 314p.

Gültekin, H. C. (2010). Antioksidan Meyveler, Ay1 Üzümleri (Vaccinium L.), Orman ve Av Dergisi, Eylül-Ekim, 5, 49-53.

Kaya, C., Esin Yücel, E., Bayram, M., Meşe, C., Aybakan, E., Gökgöz, G., Sözer, T. T. (2016). Trabzon Hurması (Diospyros kaki L.) Bazlı Karışı Meyveli Geleneksel Marmelat Üretimi Üzerine Bir Araştırma. Atatürk Univ., J. of the Agricultural Faculty, 47 (2): 107-112.

Mercimek Takci, H. A., \& Turkmen, F. U. (2016). Extracellular pectinase production and purification from a newly isolated Bacillus subtilis strain. Int. J. Food Prop., 19(11), 2443-2450.

Muradoğlu, F., Pehluvan, M., Gündoğdu, M., Kaya, T. (2011). Iğdır Yöresinde Yetiştirilen Bazı Kayis1 (Prunus armeniaca L.) Genotiplerin Fizikokimyasal Özellikleri ile Mineral İçerikleri. Iğdır Üniversitesi Fen Bilimleri Enstitüsü Dergisi. 1(1), 11-17.

Sànchez-Moreno, C., Plaza, L., De Ancos, B., Cano, M. P. (2003). Quantitative Bioactive Compounds Assessment and Their Relative Contribution to the Antioxidant Capacity of Commercial Orange Juices, J. Agric. Food Chem. 83; 430-439.

Uçan Türkmen, F. ve Mercimek Takci, H. A. (2018). Ultraviolet-C and ultraviolet-B lights effect on black carrot (Daucus carota ssp. sativus) juice. J. Food Meas. Charact., 12(2), 1038-1046.

Watts, B.M., Ylimaki, G.L., Jeffery, L.E., Elias, L.G. (1989). Basic Sensory Methods for Food Evaluation. The International Development Research Centre, Ottawa, Canada, 160p.

Yurdagül, E. (2007). Erik Bazlı Karışık Meyveli Geleneksel Marmelat Üretimi Üzerine Bir Araştırma. Yüksek Lisans Tezi, Çukurova Üniversitesi, Adana, 34s. 